Article

\title{
Physical Properties of Fabrics: Chemical Compositions of Se- lected Detergents on Colourfastness of GTP Wax Print and ATL Wax Print (Indigo) in Ghana
}

\author{
Grace Commey ${ }^{1 *}$, Victoria Doris Amankrah ${ }^{1}$, Anastasia Amenya ${ }^{2}$ \\ ${ }^{1}$ Department of Technical and Vocational Education and Training, Komenda College of Education, Komenda, \\ Ghana \\ ${ }^{2}$ Department of Social Sciences and Creative Arts, Evangelical Presbyterian College of Education, Amedzope, \\ Ghana \\ *Correspondence: bordohlity@yahoo.co.uk
}

How to cite this paper: Commey, G. Amankrah, D. V., \& Amenya, A. (2021). Physical Properties of Fabrics: Chemical Compositions of Selected Detergent on Colourfastness of GTP wax Print and ATL Wax Print 9Indigo) in Ghana. Journal of Art and Design, 1(1), 17-27. Retrieved from https://www.scipublications.com/journal/in-

dex.php/jad/article/view/153

Received: August 2, 2021

Accepted: November 15, 2021

Published: November 16, 2021

Copyright: (C) 2021 by the authors. Submitted for possible open access publication under the terms and conditions of the Creative Commons Attribution (CC BY) license (http://creativecommons.org/licenses /by/4.0/).
Abstract: The study sought to investigate the Physical Properties of Fabrics: Chemical Compositions of Selected Detergents on Colourfastness of GTP Wax Print and ATL Wax Print (Indigo) in Ghana. A $3 \times 2 \times 2$ factorial experiment which includes three washing cycles, the two detergents and two fabrics types were used or the study. A total of 146 specimens were cut randomly from along the warp and weft grain directions of ATL and GTP wax prints and subjected to washing and breaking at the laboratory using standard equipment. The data was analysed using Microsoft Excel 2007 version and the results were presented using means and percentage tables. One-way analysis of variance (Anova) was used to test the hypotheses formulated. The study revealed that there was no significant difference in the tensile strength between GTP and ATL wax prints after undergoing three washing cycles with Omo multiactive and Ariel enzymax. The degrading effect in terms of loss of tensile strength of Ariel enzymax on both wax prints was greater than that of Omo multiactive. There was no significant difference in the colour fastness between ATL and GTP wax prints after undergoing three washing cycles each with Ariel enzymax and Omo multiactive. It is recommended that both GTP and ATL fabric manufacturers should pay particular attention to the physical properties (such as thread count, fabric weight and weave type) when purchasing grey goods for further processing of their products. It is also recommended that, Ghana Standards Authority should make it compulsory for the manufacturers of washing detergents to indicate the correct chemical composition of their products on the packages.

Keywords: Fabrics, Chemical, Detergents, Colourfastness, GTP Wax Print, ATL Wax Print, Ghana

\section{Introduction}

Cotton fabrics are characterised by good wearing qualities, excellent launderability, good absorbency, good colourfastness if good dyes are used, easy dyeability, good pliability and flexibility, good heat resistance, finishing for resistance to shrinkage, maneuverability to form fabrics that have stretch and comfort [1]. These attributes make cotton a fabric of choice in the production of African prints produced in Ghana. InGhana, there are well-established textile factories, namely Ghana Textstyle Print (GTP), Ghana Textile Manufacturing Company (GTMC), and Akosombo Textile Limited (ATL). There are other small-scale industries that produce batik, silkscreen and tie and dye fabrics. The local textile industries in Ghana have improved their products and consumers believe they are less expensive, compared to other imported fabrics of the same category [2]. Consequently, many people, including foreigners, are buying the locally produced real wax prints not only for its affordability but also for its versatility and aesthetic appeal [2]. Since Ghanaian 
textile prints compete favourably with the imported ones, one would expect that the former would last longer to save replacement, since frequent replacements are costly.

Today's consumer is not only conscious of the style and comfort of their fabrics, but also of their care and durability [3]. Consumers always expect a certain level of usefulness in a fabric or clothing bought, and this explains why consumers are concerned about the performance of the fabrics of garments they purchase. With the rising demand of cotton fabrics, demands in term of dimensional instability, shrinkage and colour fading, in contrast to its excellent attributes, are the most critical quality problems after repeated laundering [4]. This usefulness or utilization factor expected becomes the performance of the clothing or fabric which is influenced by many variables. Some of the factors or variables as fibre quality, yarn formation, fabric construction, textile wet processes and consumer washing processes [3].

Detergents, markedly different in formulations and physical and chemical properties are widely used in the daily life of mankind and are suitable for laundry purposes such as cleaning our skin or hands and washing of clothes [5]. However, Ariel enzymax and Omo multiactive are considered to be the most common ones in the Ghanaian market according to preliminary investigation conducted by the researcher. Over the years, Omo and Ariel have been improved by the introduction of enzymes which act as catalysts to "eat" the dirty off during laundry. Their manufacturers even state that the detergents can be used in washing both printed and coloured articles or garments [5]. According to Gokilavani and Gopalakrishnan, enzymes allow detergents to effectively clean clothes and remove stains. Detergents are used for cleaning because pure water cannot remove oily organize soiling [6]. Enzymes help in achieving superior cleaning performance that requires attacking stains. Without enzymes a lot of energy would be required to create the high temperatures and vigorous shaking needed to clean clothes effectively [7].

Consumers of textile products are attracted to the colour of a fabric before considered its hand or feel. However, if consumers are to be satisfied with the fabrics they buy, the fabrics must retain the colours that attracted them to make the purchase after a reasonable period during wear and maintenance. Colour loss during maintenance of any textile item generally results in consumer dissatisfaction and premature discard of the fabric or clothing, unfortunately, no one dye is fast under all conditions of use and maintenance [1, 8]. Once clothing is purchased and worn, its serviceability is exposed to all sorts of conditions which include sunlight; humidity; atmospheric gases; wet, dry and hot conditions; perspiration and body oils; and mechanical forces such as flexing, straining and abrasion [9]. Therefore, the performance of clothing in terms of colourfastness and tensile strength cannot be told at a glance. It is impossible for even the most complex and refined laboratory test methods and duplicate the conditions under which clothing is expected to be serviceable.

Domestic washing conditions vary widely with time, temperature, detergent type and concentration which influence the performance and behavior of colour on fabrics during the life cycle of the garment [10]. When clothing is laundered, it comes into contact with lot of environmental factors such as sunlight, humidity, atmospheric gas, etc. these environmental factors can cause deterioration in clothing, leading to loss of colour, strength, dimensional stability, among others [11]. Ghana Textiles Print (GTP) and Akosombo Textile Limited (ATL) wax prints have patterns which tell stories of relevance and traditional African fables. The colours used are significant as these colours hold tribal orientation and marital status. For instance, GTP wax prints have four main classifications, namely WPI 1 1, WPN 1, WPT 1 and WPBS 1 (sepic). These are blocked to obtain WBI 1, WBINI, WBI TI and WBSI. For fancy wax, there are Daviva, Nustyle and school uniform fabric. The ATL wax fabrics are sepia prints, indigo print 1 and 2, and cracko print 1 and 2. The fancy prints are black and white, (double prints, traditional prints and Daviva). The names used for the above classification are as a result of the colours used for production [2]. 
The Ghanaian ATL and GTP wax cotton printed fabrics have universal acceptance among Ghanaian, for the very fact that they are made from cotton fabrics, and cotton does well in the Ghanaian weather condition. Consumers wash their garments often because of sweat combined with dirt from the atmosphere [12]. The periodic washing of fabrics calls for the use of detergent. Omo multiactive has been with Ghanaian for some time, whilst Ariel enzymax is relatively new in the Ghanaian market. These two detergents are the commonest used by Ghanaian consumers, according to preliminary investigation conducted. It is believed that the use of detergents on fabrics has a fascinating history and a powerful chemistry on the colour of the fabrics. It is perceived that these high enzyme detergents have effects on the fabrics such as fading of the colours of the fabrics as well as their weakening. However, there have been so many studies conducted on Ghanaian real wax prints. A study on the effects of sunlight on the colour of Ghanaian cotton printed fabric and concluded that washing per se and sunlight caused the colour of real wax, real java and batik fabrics to fade [8]. Ghana being in the equatorial region with hot climatic temperatures for most part of the year, one keeps wondering whether people who use textile fabrics consider the effect of sunlight on the textile fabrics they use. Again, are here any considerations given to the choice of soaps or detergents they use in washing textile fabrics? These and other questions prompted this study. The problem definition was therefore to examine the effects of high enzyme washing detergents (Omo multiactive and Ariel enzymax) on the performance of Ghanaian real wax cotton printed fabrics during care. The purpose of this study was to investigate the effects of Omo Multiactive and Ariel enzymax (two commonly used washing detergents on the Ghanaian markets) on the strength and colour of Ghanaian real wax cotton printed fabrics (ATL and GTP). The specific objective was to determine the colourfastness of GTP and ATL wax prints (Indigo) after washing with the selected detergents. The study was guide by these research hypotheses:

1. $\mathrm{H}_{0}$ : There is no significant difference in the colour of GTP wax cotton printed fabric after three washing cycles using Ariel enzymax.

2. $\mathrm{H}_{0}$ : There is no significant difference in the colour of ATL wax cotton printed fabric after three washing cycles using Ariel enzymax.

3. Ho: There is no significant difference in the colour of GTP wax cotton printed fabric after three washing cycles using Omo multiactive.

4. Ho: There is no significant difference in the colour of ATL wax cotton printed fabric after three washing cycle using Omo multiactive.

\section{Theoretical Framework Underpinning the Study}

This theory is also known as shear energy theory or von Mises-Hencky theory [13]. Like the maximum shear stress or Tresca failure theory, the maximum distortional energy failure theory addresses materials. This theory indicates that failure will occur when the distortion energy per unit volume due to the applied stresses in a part equals the distortion energy per unit volume at the yield point in uniaxial testing. 


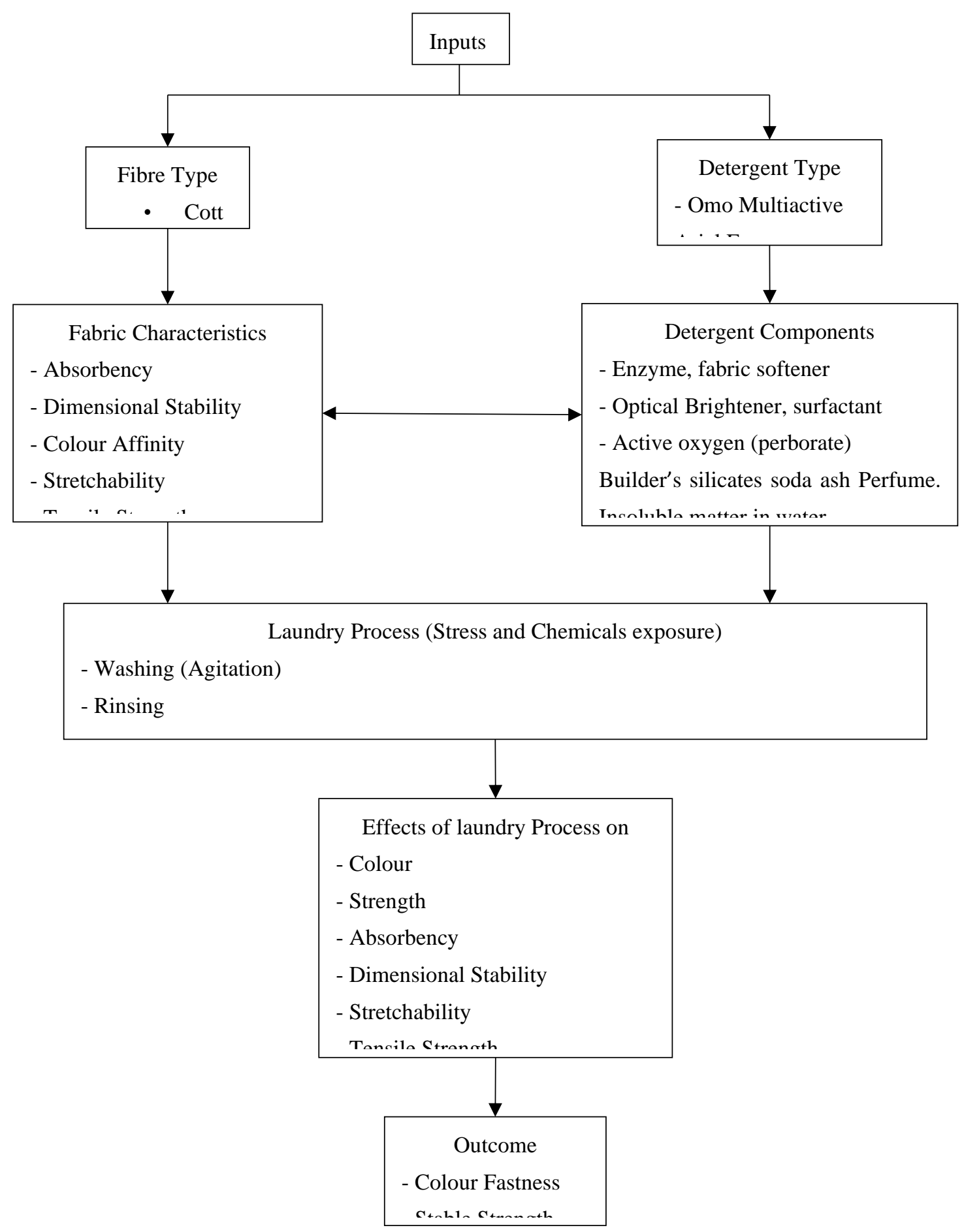

Figure 1. Conceptual Framework for the Study. Source: Author's Construct, 2012

The conceptual framework is based on eh input-output theory which assisted in experimenting the effect of high enzyme washing detergents on strength and colour of Ghanaian real wax cotton printed fabrics. Fabrics from (indigo) were used for the study. Two different washing detergents, Ariel enzymax and Omo multiactive were used (input). The cotton fabrics (input) used in the study generally possess certain characteristics which make them unique. The unique characteristics of cotton fabrics include absorbency, dimensional stability, colour affinity, stretchability, tensile strength, elasticity, versatility and lightness. The selected washing detergents are composed of elements like enzymes, 
fabric softener, optical brightener, surfactant, builders, bleaching agents, fillers, perfumes and other minor additives which give them unique characteristics.

There is the likelihood of a direct linear relationship between the chemical composition of the detergent and that of the fabric characteristics. The detergents components do have direct effects on the fabric characteristics during washing which could be positive or negative. Laundering is the process of washing clothes using water and soil removing chemicals which includes water, soap, detergent and bleaches. Cotton fabrics need to appear clean and smell pleasant during laundering. After laundering, consumers expected the characteristics are often expected by consumers to remain unchanged [14].

The first stage of the framework focuses on the stress and chemical actions during the laundry process. As explained by the failure theories, the more fabrics are subjected to stress such as washing, their performances are likely to be different. Wax prints (inputs) are taken through the laundry process, that is through immersing them in detergent solutions for some considerable amount of time 30,60 and 90 minutes intermittently and agitated. The fabric is then exposed to the chemical solutions rinsed in clean cold water to get rid of all detergent solution used for washing the fabrics. The idea was to stop the reactions that the chemicals may have on the fabric. Moisture has to be removed from the fabric to bring it to the original state by drying either in the sun or in a room to prevent the effects of the sun on the fabric.

The second stage deals with the identification of the effects of the laundry process on the fabric after drying. The fabrics were conditioned inside the laboratory. The fabric characteristics which were observed in this study were colour fastness and tensile strength. The Grey Scale was used to assess the change in colour of the fabric, and Universal Tensile Testing Machine was also used to determine the break points of the fabric at different washing cycles (30, 60 and 90 minutes). At the third stage, differences in the chemical properties of detergent might have caused different effects. In the outcome, colour becomes faster and brighter, and the strength remains stable or improves after wax printed cotton fabrics go through this laundry process.

\section{Methodology}

\subsection{Research Design}

The study is an experimental research in that it considers many possible factors that might cause or influence a particular condition or phenomenon. The experimental design gave me the opportunity to manipulate the variables being used [15]. The experiment was handled as a three by two by two $(3><2 \times 2)$ factorial design. The first factor was the treatment (washing), the second factor was the detergents used (Ariel enzymax and Omo multiactive) and the last factor was fabric types (ATL and GTP real wax indigo prints which are produced from $100 \%$ cotton). These are the parameters adapted in carrying out the study. Factorial design was chosen because the study involved more than one variable.

\subsection{Materials (Populations)}

Ghana Textstyle Print (GTP) and Akosombo Textile Limited (ATL) fabrics were selected on the basis that both are real wax products and are produced using wax printing techniques. The two fabrics were both indigo prints with white as base colour purchased from the market. Indigo prints were used because both are wax prints that are subjected to the same printing technique, and the same colour would offer the same basis for comparison without other colour effects on the variable [16]

Six yards each of GTP and ATL indigo wax prints were used for the study. Two different types of washing detergents, omo multiactive and ariel enzymax were also purchased from the Ghanaian market for the study. Though there are a lot of detergents sold in the Ghanaian market, these two detergents were chosen because they are commonly 
used by a number of Ghanaian consumers, as was evident in a casual investigation carried out for the purpose of choosing the most frequently used detergents for this study.

\subsection{Sample and Sampling Procedure}

The strip test method was employed in carrying out the study. Purposive sampling procedure was used in selecting the detergents and fabrics for the study. A total of 146 specimens were cut randomly from along the warp and weft direction of the grain of GTP and ATL cotton fabrics selected The sizes for the specimens were $6 \mathrm{~cm} \times 30 \mathrm{~cm}$, which are sizes required by the. International Standard Organisation (ISO) specific text method. The procedure therefore generated 146 specimens for the experimental study. The study was limited to one colour for comparability, fair assessment and to draw meaningful conclusions. The weight of the fabric was determined by using the pattern cutter to cut standardised circular cut from the individual fabrics for the test in both warp and weft direction.

\subsection{Research Instruments}

The data for the study were collected through the use of laboratory experiment and the following instruments were used to conduct the experiment: wooden template, weighing scale, spatula, measuring tubes, beakers, launderometer, drying rack, glass cutter, pick glass/counting glass, pattern cutter, verivide colour assessment chamber, grey scale, grey mask, canisters and universal tensile testing machine. Wooden template, measuring $6 \mathrm{~cm}$ by $30 \mathrm{~cm}$, was used to measure the samples for the study, and a pair of shears was used for cutting samples for the test. Weighing scale $\mathrm{T}^{*} \mathrm{~L} / \mathrm{A} 12 / \mathrm{WGS} /$ (Adam equipment) was used to weigh specimens and detergents before washing because the weights of the fabric determine the amount of soap solution to put into each canister before washing. Spatula was also used to take the amount of detergent needed into the beaker. Measuring tubes were used to measure the amount of water needed to prepare detergent solution. The detergent solution was poured into beakers and the beakers were placed in the Eyela water bath to help dissolve the individual particles uniformly.

Launderometer (Gyro wash) T $>$ L/A12/GWM/01 model was used to wash the specimens. The launderometer is made up of stainless steel containers of $550+50 \mathrm{ml}$ capacity which rotate at the rate of $40 \pm 2 \mathrm{rpm}$. The temperature of the water bath was thermostatically controlled to maintain the test solution at the prescribed temperature of $\pm 2^{\circ} \mathrm{C}$. Drying rack was used to dry the washed specimens. Glass cutter (eye piece) was used to determine the weave in the fabric. Pick glass or counting glass was employed to determine yarn count, and pattern cutter was used to cut fabrics in circular shapes to determine the weight of the individual fabrics. Verivide colour assessment chamber was used to assess the colour of specimen for the first stage. Grey Scale was used for assessing change in colour complying with 105 - A02 and also for assessing staining, complying with 150 (105 - A03), and the grey mask was used to stabilise the fabric during measuring. Finally, universal tensile testing machine (Hounsfield) was used to test for tensile strength. It has constant rate of extension, provided with one clamp which is stationary and another clamp which moves with a constant speed throughout the test, the entire testing system being virtually free from deflection. The machine has gauge length which shows the distance between the two effective clamping points of a testing device.

\subsection{Data Analysis}

The data obtained was presented using both descriptive and inferential statistics. The descriptive statistics (frequencies, percentages, means and standard deviation) were used to analyse the data pertaining to the research hypotheses. The rationale for choosing descriptive statistics for the hypotheses was based on the assertion that descriptive statistics, means and standard deviation enable a researcher to have an overall view of the findings of the study to identify and display relationships between parts of the findings [17]. The one-way analysis of variance (ANOVA) was used to test the ten hypotheses formulated 
to guide the study. ANOVA was used because the study tested for significant differences among three variables (three washing cycles).

\section{Results and Discussions}

\subsection{Physical Properties of the Fabrics}

This section examines the physical properties of the two fabrics, in terms of the thread count, fabric weight and weaves type. These physical properties of the fabrics were examined to ascertain the influence they were likely to have on the tensile strength test. Fabric weight determines its absorbency and influences elongation in cotton fabrics. Thus, heavier cotton fabrics are likely to stretch more than lighter ones under tensile strength [1]. Similarly, since the weight of fabrics is on many occasions determined by the thread count, it is likely to play a critical role in uniaxial testing. The weave type of fabrics also plays an essential role in uniaxial testing. Weave patterns of fabrics create varying degrees of durability, which affects their performance when subjected to uniaxial testing [18]. Table 1 gives a summary of the physical properties of both ATL and GTP fabrics used in the study.

Table 1. Physical Properties of Fabrics

\begin{tabular}{ccc}
\hline Properties & ATL & GTP \\
\hline Thread count (Warp) & 82 & 81 \\
Thread count (Weft) & 64 & 63 \\
Weight & $128 \mathrm{~g} / \mathrm{M}^{2}$ & $114 \mathrm{~g} / \mathrm{M}^{2}$ \\
Weave type & Plain & Plain \\
\hline
\end{tabular}

Source: Laboratory Results, 2011

The data in Table 1 show that the average thread count in the warp direction of the ATL fabrics was 82 , while that of the weft direction was 64 . On the other hand, the average thread count in the warp direction of the GTP fabrics was 81, whereas that of the weft direction was 63. These results explain why the warp yarns of fabrics are stronger than the weft yarns. A similar study concluded that the greater the yarn count, the stronger the fabric. The average thread counts of ATL fabric from both directions were higher than those of GTP [19]. The implication is that ATL fabric is likely to have a higher breaking point than GTP when subjected to the same stress test or uniaxial testing. This corroborates the assertion that, the strength of a fabric depends on the compactness of the construction, which in turn is determined by the quantity of the yarns. A closely woven fabric shrinks less in washing, slips less at the seams and keeps its shape [18]. This property shows the importance of thread count in the uniaxial test of fabrics.

The ATL fabrics weighed more than the GTP fabrics as indicated by the average weight of the ATL fabrics which was $128 \mathrm{~g} / \mathrm{M}^{2}$, and that of GTP fabrics was $114 \mathrm{~g} / \mathrm{M}^{2}$. The difference could be attributed to the higher number of thread counts in ATL fabrics in both warp and weft directions than those in GTP fabrics. The implication is that ATL fabric is likely to resist elongation and have a higher breaking point than GTP fabric. The patterns of both fabrics were plain weave. The implication is that the weave type may have differential effect on the fabrics during tensile strength testing.

\subsection{Chemical Composition of the Detergents}

Chemical composition of detergents plays a major role in the ability of fabrics to maintain their strength and colour fastness [3]. In other words, differences in the chemical properties of detergents largely explain differences in the colourfastness of printed fabrics when they undergo washing. Detergents with high quantities of bleaching agents and optical brightness are likely to cause excess colour bleeding in printed fabrics than detergents with less of those chemical properties. The chemical composition of detergents therefore 
plays an essential role in the colourfastness test of printed fabrics. Table 2 shows the chemical compositions of the detergents in relation to standard composition requirements from the Ghana Standards Authority.

From Table 2, it can be observed that both detergents did not meet the active ingredients (surfactant), insoluble matter in water and non-detergent organic matter compositions requirements of washing detergents prescribed by the Ghana Standards Authority (GSA). These standards are used to ensure that the quality of textile fabrics (in terms of colour, weight and tensile strength) is preserved. Table 2 further shows that the active ingredients (surfactant) in both detergents were more than the required quantity of below 15 percent. The minimum composition of active matter (enzymes) in detergents was 16 percent. From the laboratory test, the active matter (enzymes) in Omo was 20 percent and that of Ariel was 17 percent, which implies that both detergents met the GSA standard composition for that ingredient.

Table 2. Chemical Composition of the Detergents

\begin{tabular}{cccc}
\hline Properties & Omo & Ariel & Standard (GSA) \\
\hline Active ingredients (surfactant) & $15 \%$ & $16 \%$ & Less than $15 \%$ \\
Active matter (enzymes) & $20 \%$ & $17 \%$ & Minimum $16 \%$ \\
Ph & $9 \%$ & $8.5 \%$ & Between 7 and 11\% \\
Insoluble matter in water & $4 \%$ & $5 \%$ & $2.5 \%$ \\
Non-detergent organic matter & $0.3 \%$ & $0.4 \%$ & $1 \%$ \\
\hline
\end{tabular}

Source: Laboratory Results, 2011

The standard composition of insoluble matter in water of washing detergents is 2.5 percent. However, it was found out in the study that the insoluble matter in water of Omo was 4 percent and that of Ariel was 5 percent. Thus, both detergents had more insoluble matter in water than what is required. The non-detergent organic matter of Omo was 3 percent and that of Ariel was 4 percent, compared to the standard requirement of 1 percent from GSA. This implies that the non-detergent organic matter composition in both detergents was more than the standard requirement.

According to Kadolph and Langford non-standardised detergents are more likely to affect the quality (colour, weight and tensile strength) of textile fabrics [19]. Thus, high concentration of certain ingredients is likely to cause excess colour bleeding in textile fabrics, reduce the weight of textile fabrics and weaken their tensile strengths. On the other hand, less concentration of certain ingredients is likely to reduce the effectiveness of the detergents during washing. As a result, the differences in the chemical composition of the detergents are likely to cause differences in the colour - fastness and tensile strength of ATL and GTP fabrics. This implies that the adherence to the standard requirements of the chemical contents in detergents is critical in maintaining the quality of textile fabrics.

\subsection{Effects of Detergents on the Colourfastness of GTP and ATL Wax Prints after Washing}

Colourfastness refers to the resistance of a material to change in any of its colour characteristics, when subjected to washing [19]. In other words, clothing is colourfast to washing if its colours and dyes do not bleed or run from the clothing during or after washing. The chemical composition of soaps and detergents, to some extent, determines the rate of colour bleeding or colourfastness of a particular textile fabric during washing. Kadolph and Langford reported that excessive or continuous bleeding of textile fabrics fades their aesthetic qualities [19]. As a result, a researcher recommended that clothing should be tested for colourfastness before using any type of bleach or bleaching solution, or strong cleaning product. This could either be done by dipping a small portion of the clothing in water to check traces of colour bleeding in the water or laying white clothing 
under the tested fabric and pouring water onto it to check traces of colour bleeding on the white clothing [20]. A study posit that the physical properties of textile fabrics play an essential role in their colourfastness [1]. To find out how authentic the assertions made by the authors listed are, a test on the effect of detergents on the colourfastness of GTP and ATL wax prints was done using Omo multiactive and Ariel enzymax. The Grey Scale, which was used to test for the colourfastness of the two wax prints, was calibrated into 1 , $1-2,2,2-3,3,3-4,4,4-5,5$. A cotton fabric passes the colourfastness test when it is able to retain at least 3-4 units of its colour on the Grey Scale.

\subsection{Effect of Omo Multiactive on the Colourfastness of GTP and ATL Wax Prints}

The focus of this test was to assertain the ability of GTP and ATL wax prints to retain their colour after undergoing washing with Omo multiactive detergent. The assumption was that the more a wax print is able to retain its colour after undergoing washing, the higher its colourfastness, quality and durability. The thickness of the yarns and the weight of textile fabrics partly determine the ability of the fabrics to retain their colour after undergoing washing [3]. Table 3 present the result of test performed.

Table 3. Colourfastness of GTP and ATL Wax Prints after Undergoing Washing with Omo Multiactive

\begin{tabular}{ccccc}
\hline Wax Prints & \multicolumn{3}{c}{ Mean Colourfastness of wax prints after three } & $\begin{array}{c}\text { Washing cy- } \\
\text { Cles }\end{array}$ \\
\hline \multicolumn{4}{c}{ Controls } \\
\hline GTP & 30 minutes & 60 minutes & 90 minutes \\
ATL & $4-5$ & 4 & $3-4$ & $4-5$ \\
\hline
\end{tabular}

Source: Laboratory Results, 2011

The control (untreated) in Table 3 represents the original colour retained in each wax print. The data show that the colour contained in both wax prints before washing measured 4-5 on the Grey Scale. After the first 30 minutes of washing with Omo multiactive, the GTP wax print was able to maintain its original colour of 4-5, but there was colour loss in GTP between the first and second washing cycles with Omo multiactive. On the other hand, the mean colourfastness of the ATL wax print was reduced to 4 . This implies that there was no colour difference in the ATL fabrics between the first and second washing cycles with Omo multiactive. The mean colourfastness of both GTP and ATL wax prints after 60 minutes of washing with Omo multiactive was 4 each.

The implication is that the fixative attached to GTP was more than ATL and as a result GTP was able to retain more colours compared to ATL at the first washing cycle. Another reason for GTP retaining its colour at the first washing cycle could be due to 30minute duration. According to Priest and Pullen (1990), washing of fabrics within short time will not give the true performance of fabrics.

After the third washing cycle with Omo multiactive, the colourfastness of both GTP and ATL wax prints was reduced to 3-4 on the Grey Scale. Hence, the mean colourfastness of the two wax prints reduced as they were subjected to more and more washing with Omo multiactive detergent. The results agree with the failure theories which posit that as more and more materials are subjected to stress, their qualities such as colour, weight and strength begin to fail. The implication is that Omo multiactive had an effect on the colourfastness of the two wax prints. The effects could be attributed to the non-conformity of Omo multiactive to the standardised chemical composition of washing detergents. Soaps and detergents contribute essentially to the colour bleeding of textile fabrics during washing [20].

Table 7 further reveals that both wax prints passed the colourfastness test. That meant the ranges fell within the acceptable levels of the test procedure after undergoing three washing cycles with Omo multiactive. The inference was from the fact that both wax 
prints were able to retain the ISO preferred ranges of acceptable colourfastness thresholds of between 3-4 and 5 at each washing cycle with Omo multiactive. Again, Table 3 shows that there was little difference between GTP and ATL wax prints after undergoing three washing cycles with Omo multiactive. Thus, after the first washing cycle, both wax prints recorded the same colour retention of 4 and 3-4 as measured on the Grey Scale. This may be attributed to the similarities in the physical properties in terms of the thread count and weave type, as well as the same original mean colour of the two fabrics. There was the need to test whether there was a significant difference between GTP and ATL wax prints after undergoing three washing cycles with Omo multiactive. ANOVA was used to test the statistical significant differences between the observed colourfastness test of GTP and ATL wax prints.

A p-value of 0.16 was obtained implying that there was no significant difference between GTP and ATL wax prints after undergoing three washing cycles at an alpha value of 0.05. In other words, the mean colourfastness of the GTP wax prints after the three washing cycles was not significantly different from the ATL wax prints after undergoing three washing cycles with Omo multiactive. This Means Omo multiactive detergent has similar effects on both GTP and ATL wax prints. The non-significant difference between GTP and ATL wax prints could be attributed to the differences in the physical properties of the two wax prints in terms of their thread count (warp and weft) and weave type.

\section{Conclusions and Recommendations}

The study revealed that, there was no significant difference in the tensile strength between GTP and ATL wax prints after undergoing three washing cycles with Omo multiactive and Ariel enzymax. This was attributed to the similar characteristics born by the two wax prints. In other words, there should be a significant difference in the physical properties of fabrics before a significant difference could be established between them during failure test. The two wax prints performed better with Omo multiactive than with Ariel enzymax. This was attributed to the differences in the chemical compositions of the two detergents. The implication is that similarities in the physical properties of fabrics are more likely to result in similar degrading effect when they are subjected to same or similar stress.

It is recommended that, both GTP and ATL fabric manufacturers should pay particular attention to the physical properties (such as thread count, fabric weight and weave type) when purchasing grey goods for further processing of their products. This is because the physical properties determine the durability of the textile fabrics in terms of their colourfastness and tensile strength. As a result, increasing the compatibility of the yarns and using filament yarns with high tensional properties to increase the weight will help to improve the colourfastness and tensile strength of the fabrics, which would further help to improve the market image of products. This will make locally manufactured textile fabrics more competitive with the imported ones.

It is also recommended that, Ghana Standards Authority should make it compulsory for the manufacturers of washing detergents to indicate the correct chemical composition of their products on the packages. This will enable consumers to compare the chemical contents of washing detergents and their likely effect. The on their textile fabrics before purchasing a particular detergent. It will also enable manufacturers of detergents to conform to the standard chemical composition of washing detergents.

Author Contributions: Conceptualization, GC, VDA, and AA; methodology, GC and VDA.; validation, GC, VDA, and AA; formal analysis, GC.; investigation, GC.; resources, GC.; data curation, C.K.; writing-original draft preparation, GC.; writing-review and editing, AA.; visualization, C.K.; supervision, GC.; project administration, GC and VDA. All authors have read and agreed to the published version of the manuscript. 
Funding: "This research received no external funding"

Data Availability Statement: Data is available on request from the corresponding author.

Acknowledgments: we acknowledge the Dr. Anthony Bordoh for his input and suggestions

Conflicts of Interest: "The authors declare no conflict of interest." "No funders had any role in the design of the study; in the collection, analyses, or interpretation of data; in the writing of the manuscript, or in the decision to publish the results".

\section{References}

[1] Joseph, M. L. (1988). Introductory textile science (3 ${ }^{\text {rd }}$ ed.). New York: Holt.

[2] Estey, W. (2008). The story behind African wax cloth. Retrieved on December 16, 2020 from http://www.thewrendesign.com/the-story-behind

[3] Amankrah, D. V., Koranteng, M., \& Nyadroh, A. A. P. (2021). An Appraisal of Washing Cycles on the Colours of Akosombo Textile Limited and Dong Yu Textile Company Limited Kente Printed Fabrics in Ghana. American Journal of Marketing Research, $7(2), 17-26$

[4] Vargas, Mary (2009). Fashion Statement or Political Statement: The Use of Fashion to Express Black Pride during the Civil Rights andBlack Power Movements of the 1960's. Undergraduate Review, 5, 95-99. Available at: http://vc.bridgew.edu/undergrad_rev/vol5/iss1/19

[5] Unilever. (2012). Key soap: Amansan boafo. Retrieved August 17, 2020, fromhttp://www.unileverghana.com/brands/homecarebrands/Keysoap. aspx

[6] Gokilavani, R., \& Gopalakrishnan, D. (2002). Bio technology textiles. Future trend. Retrieved on $16^{\text {th }}$ July, 2013 from dgkpsgtech@yahoo.com.

[7] Outwater, A. (1966). How enzymes are changing your wash. Retrieved on Saturday, November 12, 2011 from http://www.home-hawstuffworks.com/laundry-detergenthtml

[8] Fianu, D. A. G, \& Adams, M. (1998). The effect of sunlight on the colour of Ghanaian cotton printed fabrics. Journal of Consumer Studies $\mathcal{E}$ Home Economics, 22 (1), 15-18.

[9] Kahabka, B. (1970). Clothing serviceability. [Online] Available at Karmakar, S. R. (1999). Chemical technology in the pre-treatment processes of textiles. New York: Elsevier Publishing Company.

[10] Ferguson, A. (2008). Effect of laundry detergents and residual alkali on the light fastness. New York. Avenue Pub. Group

[11] Haider, Z. M. (2007). "Competitiveness of the Bangladesh ready-made garment industry in major international markets". AsiaPacific Trade and Investment Review, 3(1), ISBN: 978-92-1-120519-0, ISSN: 1815-8897

[12] Fianu, D. A. G, Sallah, R. A , \& Ayertey, A. (2005). The effect of sunlight and drying methods on the strength of Ghanaian Real Wax printed fabrics. retrieved on $25^{\text {th }}$ April, 2020 from International Journal of Consumer Studies, 29 (1). 34-40.

[13] Von Mises, R. (1913). Mechanik der festen Korper im plastisch deformablen Zustand Gottin Nachr. Mathematics and Physics, 1, 582-5.

[14] Priest TF, And Pullen JA (1990). Guide to Clothing. California: McGraw Hill Company.

[15] Leedy, P. D., \& Ormond, J. E. (2002). Practical research: Planning and design^ed.). New Jersey: Prentice Hall.

[16] Ghana Standards Authority (1970). Standard for real wax and wax block printed cloth. Accra: Ghana Standards L5, UDC.

[17] Sarantakos, S. (1998). Research and paradigms. Retrieved on October 15, 2020 from www.umdj. edu/idsweb/idst600/willian.

[18] Corbman, B. P. (1983). Textile and Fashion Technology. Retrieved on 15 th June, 2012 from http://www.mu.acin/syllabus/4.34\%20TYBSC.\%

[19] Kadoph, S. J., \& Langford, A. I. (2002). Textiles (9th ed). Upper Saddle River, NJ: Prentice-Hall.

[20] Liz, W. (2010). "Capturing the Landscape: Textiles for the Australian Fashion Industry". Textile Society of America Symposium Proceedings. 61, 1-9. 